\title{
INTERPRETIVE SUMMARIES, SEPTEMBER 2012
}

Invited review: Strategies for promoting productivity and health of dairy cattle by feeding nonforage fiber sources. By Bradford and Mullins, page 4735. Incorporating nonforage fiber sources into lactating dairy cattle diets provides an opportunity to improve farm profitability through decreased feed costs and possibly increased milk production. Several factors need to be considered when incorporating these ingredients into lactation diets, and conventional formulation guidelines may not apply when feeding these ingredients in large quantities. Diets formulated to complement the characteristics of any nonforage fiber sources, rather than a single substitution for an ingredient, will enhance the likelihood of optimizing its use.

The evolution of chemical and microbiological properties of fresh goat milk cheese during its shelf life. By Masotti et al., page 4760. Retail storage conditions (i.e., time, temperature, lighting, and packaging) were investigated for their effects on the chemical and microbiological properties of fresh goat milk cheese. Only slight modifications of $\mathrm{pH}$, dry matter, and water activity values were recorded after $45 \mathrm{~d}$ of storage. Proteolysis proceeded as a result of the storage temperature and activity of the retained chymosin. Dark storage slowed oxidation and hexanal formation, and cheeses stored in these conditions showed higher sensorial quality compared with those kept under light.

Fortification of cheese with vitamin $D_{3}$ using dairy protein emulsions as delivery systems. By Tippetts et al., page 4768. The objective of this study was to fortify cheese with vitamin $\mathrm{D}_{3}$ and increase its retention using different dairy protein-based oil-in-water emulsions. Vitamin $\mathrm{D}_{3}$ was incorporated as part of the oil phase of an oil-in-water emulsion, which was then mixed into the milk before making cheese. Vitamin $\mathrm{D}_{3}$ retention in cheese curd formulated with the vitamin $\mathrm{D}_{3}$ emulsions increased compared with that obtained using a nonemulsified form of vitamin $\mathrm{D}_{3}$. The retention of vitamin $\mathrm{D}_{3}$ observed in the emulsion-fortified curds was not affected by the type of protein used during emulsion formulation.

Antibiotic resistance of lactic acid bacteria isolated from Chinese yogurts. By Zhou et al., page 4775. The aim of this study was to evaluate the susceptibility of 43 strains of lactic acid bacteria, isolated from Chinese yogurts made in different geographical areas, to 11 antibiotics. Random amplification of polymorphic DNA (RAPD) analysis was used to differentiate 18 Lactobacillus bulgaricus and 25 Streptococcus thermophilus strains. In total, 35 genotypically different strains were detected and their antimicrobial resistance to 11 antibiotics was determined using an agar dilu- tion method. Multidrug resistance to antibiotics was found and common antibiotic resistance genes $[\operatorname{tet}(\mathrm{M})$, $\operatorname{ant}(6), \operatorname{aph}\left(3^{\prime}\right)$-IIIa] were detected.

Accelerated ripening of Caciocavallo Pugliese cheese with attenuated adjuncts of selected nonstarter lactobacilli. By Di Cagno et al., page 4784. Selected nonstarter lactobacilli used as attenuated adjunct cultures were suitable for making ripened pasta filata cheeses such as Caciocavallo Pugliese. Microbiological, biochemical, and sensory analyses showed that acceleration of Caciocavallo Pugliese cheese was achieved without modification of the main features of the traditional cheese (made without adjuncts).

Effect of fat content and homogenization under conventional or ultra-high-pressure conditions on interactions between proteins in rennet curds. By Zamora et al., page 4796. Ultra-high-pressure homogenization (UHPH) is a novel technology that homogenizes milk at much higher pressures than those commonly used in the food industry (up to $300 \mathrm{MPa}$ ). Previous studies have shown that UHPH alters the technological characteristics of milk for cheesemaking and the characteristics of resulting fresh cheeses. Such alterations could be explained in part by qualitative and quantitative differences observed in the present study in the interactions between proteins within drained rennet curds as affected by 2 factors: fat content of milk and homogenization treatment.

Strain-level characterization of nonstarter lactic acid bacteria in Norvegia cheese by highresolution melt analysis. By Porcellato et al., page 4804. The secondary microflora of Norvegia, a Goudatype cheese, was investigated by combining 2 molecular techniques, $16 \mathrm{~S}$ ribosomal RNA gene analysis and repetitive element (rep)-polymerase chain reaction analysis by high-resolution melt analysis (HRM), for characterization of 94 pure cheese isolates. Three species of mesophilic Lactobacillus were present, and the study of the phylogenetic relationship between the isolates highlighted a greater variation between the isolates of Lactobacillus paracasei/casei than Lactobacillus plantarum/Lactobacillus pentosus. We recommend HRM as a high-throughput screening method, because it is a fast (20 min), single-step, post-PCR technique without any PCR product handling and with no need for hazardous chemicals.

Bovine milk contains microRNA and messenger RNA that are stable under degradative conditions. By Izumi et al., page 4831. MicroRNA (miRNA), one type of noncoding small RNA, plays important roles in a wide range of physiological processes. We 
previously reported that human breast milk contains miRNA. In this study, we found that bovine milk also contains miRNA. We also confirmed that some messenger RNA (mRNA) are present in bovine milk. These miRNA and mRNA were resistant to acidic conditions and ribonuclease treatment. Our results indicate that functional RNA might be new nutritional agents in bovine milk.

Technical note: Development of a quantitative PCR method for monitoring strain dynamics during yogurt manufacture. By Miller et al., page 4868. Starter cultures used in the manufacture of yogurt may consist of multiple strains of Lactobacillus delbrueckii ssp. bulgaricus and Streptococcus thermophilus. The objective of this study was to develop a quantitative polymerase chain reaction method for quantification of individual strains in a commercial yogurt starter culture. This method can be applied to evaluate the effect of formulation or processing changes on strain balance.

Evaluation of milk yield losses associated with Salmonella antibodies in bulk-tank milk in bovine dairy herds. By Nielsen et al., page 4873 . The effect of Salmonella introduction on milk yield in 28 Danish dairy cattle herds was evaluated. All but second-parity cows had reduced milk yield 7 to 15 mo after the estimated date of introduction of Salmonella into the herd, compared with cows of the same parity from the same herds in the 12 mo before introduction. These results can be used by farmers and the dairy industry to quantify production and economic losses from decreased milk yield following introduction of Salmonella into dairy herds.

Routine detection of hyperketonemia in dairy cows using Fourier transform infrared spectroscopy analysis of $\beta$-hydroxybutyrate and acetone in milk in combination with test-day information. By van der Drift et al., page 4886. The objective of this study was to develop and evaluate a diagnostic model based on acetone and $\beta$-hydroxybutyrate (BHBA) concentrations in milk in combination with available test-day information for the detection of hyperketonemia (based on plasma BHBA concentration) in early lactation dairy cows. Acetone and BHBA in milk were determined by Fourier transform infrared spectroscopy. The developed diagnostic model was suited for test day monitoring for hyperketonemia, provided that limitations of this method are taken into account.

Transmission dynamics of intramammary infections with coagulase-negative staphylococci. By Reksen et al., page 4899. Data from two US dairy herds were used to study transmission of coagulase-negative staphylococci (CNS). A low contagiousness of CNS intramammary infections (IMI) was observed on both farms studied. Infections outside the lactation period were required to maintain a stable endemic prevalence of IMI by CNS in lactating cows. An ongoing CNS IMI in one quarter significantly increased the risk of infection in another quarter in the same cow on one of the farms but not the other. Transmission of CNS was considered contagious on one farm but no distinction between contagious and environmental transmission could be made on the other. Between-farm difference may be due to diversity between prevailing CNS species or management differences or a combination of both.

Protein and fat mobilization and associations with serum $\beta$-hydroxybutyrate concentrations in dairy cows. By van der Drift et al., page 4911. Thirty-four dairy cows were monitored from 4 wk before until 8 wk after calving to study muscle (protein) and fat mobilization and associations with serum $\beta$-hydroxybutyrate concentrations. One of the measured indicators for protein mobilization was the plasma 3-methylhistidine concentration of cows. Large variations in periparturient protein and fat mobilization were observed. Mobilization of muscle started before calving in most cows. With the exception of 3 cows with severe hyperketonemia, cows with lower plasma 3-methylhistidine concentrations had higher serum $\beta$-hydroxybutyrate concentrations. The role of protein mobilization in the etiology of hyperketonemia in cows is worthy of further investigation.

Molecular epidemiology of Staphylococcus aureus mastitis in dairy heifers. By Anderson et al., page 4921. Staphylococcus aureus is a significant mastitis pathogen in dairy heifers. The origins of Staph. aureus mastitis in heifers are poorly understood but important when addressing disease management. Sources of Staph. aureus infection of the mammary gland of heifers were investigated. Isolates of Staph. aureus obtained from intramammary sites, heifer body sites, and humans were compared using molecular techniques. Indistinguishable Staph. aureus genotypes were found in horn flies (Haematobia irritans), heifer body sites, and from milk and colostrum samples. No human genotypes were associated with cows or heifers. Several sources, including horn flies, appear to be important in the epidemiology of Staph. aureus mastitis in heifers.

Effect of an automated dipping and backflushing system on somatic cell counts. By Olde Riekerink et al., page 4931. Postmilking teat disinfection is an effective management practice to prevent transmission of contagious mastitis pathogens from cow to cow. The objective of this study was to evaluate the effect of introducing an automated dipping and backflushing (ADB) milking unit system in a herd on bulk milk somatic cell count (SCC), individual cow SCC, and the 
occurrence of newly elevated SCC. Dipping, spraying, and installing an ADB system for postmilking teat disinfection was compared on 75 farms. Installing an ADB system decreased bulk milk SCC, individual cow SCC, and the occurrence of newly elevated SCC. The effect was most prominent approximately 6 mo after installation.

The effects of experimentally induced Escherichia coli mastitis and flunixin meglumine administration on activity measures, feed intake, and milk parameters. By Yeiser et al., page 4939. The present study examines the effect of experimentally induced mastitis and antiinflammatory drug therapy on animal activity, feed intake and milk production. Mastitis, a disease that negatively affects well-being, caused reduced lying times and increased standing times compared with nondiseased animals. Administration of the antiinflammatory drug during Escherichia coli mastitis improved feed intake and milk production compared with those animals who did not receive the therapy during mastitis. These results indicate that the administration of an antiinflammatory drug during clinical mastitis may help to improve some aspects of animal well-being.

The effect of respiratory disease and a preventative antibiotic treatment on growth, survival, age at first calving, and milk production of dairy heifers. By Stanton et al., page 4950. Bovine respiratory disease complex (BRD) is a common disease in weaned dairy calves. The objectives of the current study were to evaluate the long-term effects of BRD and antibiotic treatment on growth of heifers until breeding age, age at first calving, incidence of dystocia, milk production, mortality prior to first calving, and mortality prior to 120 days in milk. Bovine respiratory disease was associated with decreased growth and increased age at first calving, dystocia, and mortality. These outcomes are important because of their economic and animal welfare cost.

The welfare of dairy cows is improved in relation to cleanliness, integument alterations on the hocks and lameness when sand is used as stall surface. By Andreasen and Forkman, page 4961. Stall surface has an important effect on the welfare of dairy cows. The association between welfare and stall surface was investigated. Cows from 37 Danish dairy farms were examined. A difference in the welfare of the cows in relation to stall surfaces (rubber mats, mattresses, and sand) was found. Cows housed in facilities with freestalls containing sand had cleaner teats and hocks and fewer integument alterations on the hock, and they produced more milk. Fewer of these cows were lame.
Sampling cows to assess lying time for on-farm animal welfare assessment. By Vasseur et al., page 4968. Measures of time spent lying down may be useful measures to assess the welfare of dairy cows. For cows in tiestalls and freestalls, we examined how number of days sampled, parity, stage of lactation, and milk production affected measures of lying time. Lying time was monitored automatically for $10 \mathrm{~d}$ using data loggers. It is necessary to sample cows based on their stage of lactation and parity, but probably not milk production, to obtain a representative measure for the herd. Four days is a suitable length of sampling period to accurately estimate lying time of a herd.

Variance components of teat dimensions in dairy cows and associated factors. By Zwertvaegher et al., page 4978. Teat length and teat diameter measurements of almost 1,000 dairy cows were performed in both a cross-sectional and a longitudinal study. The majority of the variation in teat dimensions was present at the cow level or within-cow level. Because the least variation in teat length and diameters was present at the herd level, choosing a teatcup liner that is identical for all cows within a herd is far from optimal. Quarter position (front versus hind), parity, and lactation stage were identified as factors associated with teat dimensions.

Pleiotropic effects of polymorphism of the gene diacylglycerol- $O$-transferase 1 in the mammary gland tissue of dairy cows. By Mach et al., page 4989. The effect of the diacylglycerol- $O$-transferase 1 (DGAT1) gene polymorphism on milk composition and gene expression in the mammary gland tissue was evaluated in grazing dairy cows. The DGAT1 polymorphism affects the expression signatures associated with cell signalling, immune system response, and lipid biosynthesis in the mammary gland tissue, in addition to affecting quality aspects of dairy milk. These observed differences in transcriptional activity may reflect countermechanisms of mammary gland tissue to respond to changes in milk fatty acid concentration and composition.

A cohort study of the associations between udder conformation, milk somatic cell count, and lamb weight in suckler ewes. By Huntley et al., page 5001. Poor udder conformation and teat position were associated with high somatic cell count (SCC) in ewes suckling lambs (suckler ewes). Both poor udder conformation and high SCC were associated with rearing lighter lambs to $10 \mathrm{wk}$ of age. To date, no attempt has been made to select suckling ewes with good udder conformation and teat position. If these phenotypes are as heritable in dairy sheep as reported in dairy cows, then rapid improvement in udder conformation and 
teat position could be achieved. This in turn would reduce intramammary infection and improve the growth of suckling lambs.

Nonesterified fatty acids modify inflammatory response and eicosanoid biosynthesis in bovine endothelial cells. By Contreras et al., page 5011. Intense lipid mobilization in transition cows may alter vascular inflammatory responses and contribute to increased disease susceptibility. This study evaluated endothelial cells responses to conditions that mimic lipid mobilization. High nonesterified fatty acid (NEFA) concentrations increased vascular phospholipid content of stearic acid and decreased long-chain polyunsaturated fatty acids. The expression of vascular proinflammatory cytokines, adhesion molecules, and lipid mediator enzymes also increased in response to high NEFA concentrations. This research described, for the first time, specific changes in vascular inflammatory responses during in vitro exposure to fatty acid mixtures that mimic lipid mobilization during the transition period.

Nitrogen metabolism and rumen microbial enumeration in lactating cows with divergent residual feed intake fed high-digestibility pasture. By Rius et al., page 5024. Early lactation dairy cows selected for divergent residual feed intake (RFI) were fed a high-quality pasture to determine nitrogen digestibility and partitioning. We observed no differences in nutrient intake and rumen microflora between phenotypes. However, cows selected for efficient use of feed had greater nitrogen digestibility and less fecal nitrogen output.

Effect of cooling heat-stressed dairy cows during the dry period on insulin response. By TaO et al., page 5035. We evaluated the effect of cooling prepartum heat-stressed (HT) dairy cows on insulin response. Cows were kept in 2 groups-HT or cooling (CL) - from dry-off to calving. Relative to HT, CL cows had higher nonesterified fatty acid (NEFA), lower glucose and insulin concentrations, slower glucose clearance to glucose tolerance test, and weaker glucose response to insulin challenge in early lactation. No differences in metabolic responses were observed before calving. Cooling prepartum HT cows decreased peripheral tissue insulin response in early lactation.

Bioavailability of the flavonol quercetin in cows after intraruminal application of quercetin aglycone and rutin. By Berger et al., page 504\%. The plant-derived flavonol quercetin is associated with various health-promoting effects. Whereas bioavailability of quercetin has been repeatedly investigated in monogastric species, knowledge about its bioavailability in ruminants is absent. Therefore, we investigated bioavailability of quercetin from 2 different sources (quercetin aglycone, rutin) in nonlactating dairy cows. Unlike in monogastric species, bioavailability of quercetin from rutin is substantially higher compared with that from quercetin aglycone after intraruminal (or oral) application. Plasma concentrations achieved with $50 \mathrm{mg}$ of quercetin $/ \mathrm{kg}$ of body weight administered as rutin are in the range where biological effects have been described in monogastric species.

Epidemiology of subclinical ketosis in early lactation dairy cattle. By McArt et al., page 5056. The objective of this study was to describe the epidemiology of subclinical ketosis in dairy cows in early lactation and to determine the association of time and severity at onset with development of displaced abomasum and removal from herd in the first $30 \mathrm{~d}$ of lactation, early lactation milk yield, and reproduction. Cows that developed subclinical ketosis within 1 wk after calving were more likely to have adverse health events and produced less milk than cows that developed subclinical ketosis after the first week of lactation. These negative consequences worsened as the concentration of blood $\beta$-hydroxybutyrate increased.

Effect of enterotoxigenic Escherichia coli vaccine on innate immune function of bovine mammary gland infused with lipopolysaccharide. By Morimoto et al., page 506\%. We investigated the effect of enterotoxigenic Escherichia coli vaccine on the innate immune reaction in the mammary gland after intramammary lipopolysaccharide (LPS) infusion. The mean somatic cell count in milk from vaccinated cows at 12 and $55 \mathrm{~h}$ was significantly lower than that of control cows. Lingual antimicrobial peptide concentration and lactoferrin concentration in milk were significantly lower at 8 and $55 \mathrm{~h}$, respectively, in vaccinated cows than in control cows. Vaccination suppressed the innate immune reaction after intramammary LPS infusion.

Differences between coagulase-negative Staphylococcus species in persistence and in effect on somatic cell count and milk yield in dairy goats. By Koop et al., page 5075. This paper explored differences in pathogenicity between coagulase-negative staphylococci (CNS) species causing intramammary infections in goats as measured by their persistency and effect on somatic cell count and milk yield. Differences between species in effect on somatic cell count were small and the effect was limited compared with the effect of Staphylococcus aureus. The relationship with milk yield was positive for Staphylococcus caprae and nonsignificant for other CNS species, whereas the estimate for Staphylococcus xylosus was negative and comparable with the negative effect of Staph. aureus. This research implies that some CNS species may be more pathogenic than others. 
Short communication: Characterization of early postpartum estrous behavior and ovulation in lactating dairy cows using radiotelemetry. $B y$ Johnson et al., page 5085. HeatWatch II, a radiotelemetric 24-hour estrous detection system, was used to monitor early postpartum estrous behavior in 50 cows on a commercial dairy in southern Idaho. By using HeatWatch II in conjunction with progesterone analyses of blood samples and ovarian ultrasonography, we determined that $88.4 \%$ of first ovulations were not associated with behavioral estrus.

Short communication: Expression of peptide YY, proglucagon, Y2 and glucagon-like peptide-1 receptors, in bovine peripheral tissues. By Pezeshki et al., page 5089. Peptide YY (PYY) and glucagon-like peptide-1 (GLP-1) are lower gut hormones that are important for regulation of energy balance in monogastrics; little is known of the functions of these peptides in cattle. We demonstrated that the messenger RNA of PYY, Y2 receptor, and proglucagon were expressed in multiple gut segments in calves. We also showed that GLP-1 receptors were expressed in multiple peripheral tissues, including the gut. Our findings support that PYY may control gut functions, whereas GLP-1 may regulate multiple physiological functions in cattle.

Short communication: Glucose and fructose concentrations and expression of glucose transporters in 4- to 6-week pregnancies collected from Holstein cows that were either lactating or not lactating. By Lucy et al., page 5095. Glucose is an essential nutrient for the conceptus, and it is decreased in blood during lactation in dairy cows. The objective was to determine if lactation affected the amount of glucose crossing the placenta. Pregnancies collected from lactating cows had less glucose in placental fluids perhaps because of the composition of glucose transporters found in placenta. Less glucose crossing the placenta may predispose lactating cows to slower fetal development and fetal loss.

Short communication: Presynchronization for timed artificial insemination in grazing dairy cows by using progesterone for 14 days with or without prostaglandin $F_{2 \alpha}$ at the time of progesterone withdrawal. By Escalante et al., page 5102. Progesterone-containing devices can be inserted intravaginally for $14 \mathrm{~d}$ to presynchronize the estrous cycle for timed artificial insemination (TAI). The objective was to test the effect of a luteolytic dose of prostaglandin $\mathrm{F}_{2 \alpha}\left(\mathrm{PGF}_{2 \alpha}\right)$ at progesterone removal for increasing conception rate to a subsequent TAI in dairy cows. Treating with $\mathrm{PGF}_{2 \alpha}$ at progesterone removal increased the percentage of cows that came into estrus but did not cause a significant increase in conception rate to the subsequent TAI, perhaps because the im- provement in presynchronization estrus response was relatively small. A 14-d progesterone program can be used in postpartum dairy cows for TAI but it is not necessary to treat cows with $\mathrm{PGF}_{2 \alpha}$ at device removal.

Effects of different sources and levels of dietary gossypol on gossypol residues in plasma and milk of lactating cows. By Wang et al., page 512\%. Tissues or milk highly contaminated with gossypol could have detrimental effects when consumed by humans. In this experiment, 40 lactating cows were randomly assigned to 5 treatments to investigate effects of different sources and levels of dietary gossypol on gossypol residues in plasma and milk. No adverse effects were found on cows fed diets containing free gossypol from cottonseed meal or whole cottonseed.

Nutrient demand interacts with grass maturity to affect milk fat concentration and digestion responses in dairy cows. By Kammes and Allen, page 5133. Orchardgrass was chopped early (less mature) or late (more mature), ensiled, and included as the sole source of forage in total mixed rations at $25 \%$ forage neutral detergent fiber (NDF). Increasing grass maturity increased milk yield and chewing time and decreased milk fat concentration, ruminal turnover rate, and digestibility of NDF, but grass maturity did not affect feed intake or ruminal $\mathrm{pH}$. When orchardgrass silage was the only source of forage in the diet, increasing maturity did not adversely affect feed intake or fat-corrected milk yield.

Effects of the early social environment on behavioral responses of dairy calves to novel events. By De Paula Vieira et al., page 5149. Dairy calves are typically separated from the dam soon after birth and housed individually for the first weeks of life. However, under naturalistic conditions, calves interact with the dam as well as with companions of the same age and older. Social interactions early in life may influence cognitive and social development. This study compared the behaviors of calves housed individually with those of calves housed in pairs, and the behaviors of calves housed with same-aged calves with those of calves housed with an older companion. Calves reared individually were more reactive to a novel environment and to mixing with an unfamiliar calf compared with those calves reared in pairs. Calves reared in groups of similarly aged calves were more reactive to an unfamiliar calf compared to calves reared with an older companion.

Life-cycle assessment of greenhouse gas emissions from dairy production in Eastern Canada: A case study. By Mc Geough et al., page 5164. We conducted a life-cycle assessment to determine the greenhouse gas (GHG) emissions associated with a 
typical nongrazing simulated dairy farm in Eastern Canada. Methane $\left(\mathrm{CH}_{4}\right)$ from feed digestion in the animal and manure was the predominant gas emitted, followed by nitrous oxide. Lactating cows had the highest contribution to the total GHG output, with a negligible contribution from animals less than 12 mo of age. Thus, the greatest reductions in GHG emissions would be achieved by applying strategies to mitigate enteric $\mathrm{CH}_{4}$ emissions from the lactating cow.

Glycerol inhibition of ruminal lipolysis in vitro. By Edwards et al., page 5176. Glycerol is a by-product of biodiesel production and we investigated its use in the laboratory as a feed additive to improve the quality of meat and milk produced from cattle. We found that even small amounts of glycerol, those well within the range considered to be safe for animal health and function, achieved beneficial effects on fat digestion by preventing the bioconversion of healthy unsaturated fats to less desirable saturated fats.

Effect of conventional and intensified milk replacer feeding programs on performance, vaccination response, and neutrophil mRNA levels of Holstein calves. By Hengst et al., page 5182. This study evaluated the effect of conventional or intensified milk replacer feeding programs on growth and immune measures of neonatal dairy calves. The intensified milk replacer feeding program increased body weight, fecal scores, and respiratory scores. Feeding program did not affect antibody response to a novel antigen, but the intensified program increased neutrophil messenger RNA levels of L-selectin.

Milk fat responses to dietary supplementation of short- and medium-chain fatty acids in lactating dairy cows. By Vyas et al., page 5194. Milk fat is composed of short-and medium-chain fatty acids synthesized in the mammary gland and long-chain fatty acids derived from blood. Previous studies have reported that the availability of short- and mediumchain fatty acids might be limiting for milk fat synthesis. To test this, we supplemented incremental amounts of short- and medium-chain fatty acids in the diet of lactating cows. Whereas milk fat percentage increased linearly with fatty acid supplementation, we observed no effect on total milk fat yield.

The effects of fermented soybean meal on immunophysiological and stress-related parameters in Holstein calves after weaning. By Kim et al., page 5203. Weaning as a key stressor in animal production could affect not only calf health but, subsequent growth performance. Therefore, active research efforts have been devoted to develop strategies on reducing weaning stress. Fermented soybean meal could be considered as a calf additive to improve the health and growth performance of weaned calves because of improved nutritional quality and immune modulatory functions. The aim of this study was to investigate the effects of fermented soybean meal on immune and stress response in Holstein calves after weaning.

Effects of wet corn gluten feed on ruminal $\mathrm{pH}$ and productivity of lactating dairy cattle fed diets with sufficient physically effective fiber. By Sullivan et al., page 5213. Four levels of wet corn gluten feed were fed to lactating Holstein cows with at least $10 \%$ of ration particles greater than $19 \mathrm{~mm}$ long. As wet corn gluten feed increased in the diet, dry matter intake (DMI) and milk yield increased and ruminal $\mathrm{pH}$ and energy-corrected milk per unit DMI were both maintained. Additionally, cows sorted in favor of the long particles with increasing wet corn gluten feed. Carefully monitoring particle length can help maintain a healthy rumen environment while taking advantage of production responses to high inclusion rates of wet corn gluten feed.

Rapeseed or linseed supplements in grass-based diets: Effects on milk fatty acid composition of Holstein cows over two consecutive lactations. By Lerch et al., page 5221. Effects of dietary linseed or rapeseed supplements on milk fatty acid composition were determined over 2 consecutive lactations in cows fed grass silage and grass hay-based diets during indoor periods or on pasture outdoors. Oilseed supplements altered milk fatty acid composition, changes that persisted within each period and between both outdoor periods. Responses to oilseeds were of similar magnitude to that determined in shorter studies of 1 to $3 \mathrm{mo}$, but significant supplement type by basal diet interactions were identified. Dietary oilseeds decreased milk cis-9,trans-11 conjugated linoleic acid content on pasture.

Inhibition of $\Delta^{9}$-desaturase activity with sterculic acid: Effect on the endogenous synthesis of cis-9 18:1 and cis-9,trans-11 18:2 in dairy sheep. By Bichi et al., page 5242. During the last decade, research in cows and goats has shown that endogenous synthesis via $\Delta^{9}$-desaturation is the major source of some bioactive milk fatty acids, such as oleic and rumenic acids. However, no information on this issue is available in dairy sheep. The present study investigates the role of $\Delta^{9}$-desaturase in mammary lipogenesis in ewes, through administration of sterculic acid, a specific inhibitor of $\Delta^{9}$-desaturase, and provides the first estimates of endogenous synthesis of cis-9,trans-11 18:2 and cis-9 18:1 in ovine milk fat (74 and 63\%, respectively).

Effects of metabolizable protein supply and amino acid supplementation on nitrogen utiliza- 
tion, milk production, and ammonia emissions from manure in dairy cows. By Lee et al., page 5253. Dairy cows fed metabolizable protein-deficient diets supplemented with rumen-protected lysine and methionine had milk yield similar to the control cows (fed a protein-adequate diet), but milk protein content decreased without methionine supplementation. Other amino acids, possibly histidine, may be limiting milk production in protein-deficient diets. The current National Research Council (2001) protein model underpredicts milk yield in cows fed protein-deficient diets.

Use of algae or algal oil rich in n-3 fatty acids as a feed supplement for dairy cattle. By Stamey et al., page 5269. We determined the effects of lipidencapsulated algal biomass as a source of n-3 fatty acids in milk. Feeding lipid-encapsulated algae supplements may improve milk fat composition by increasing n-3 fatty acid concentrations. Rumen-protected algal biomass increased milk docosahexaenoic acid yield to a greater extent than did algal oil. Long-term feeding of lipid-encapsulated algae supplements may allow for increased docosahexaenoic acid in milk.

Transfer rate of $\alpha$-linolenic acid from abomasal infused flaxseed oil into milk fat and the effects on milk fatty acids composition in dairy cows. By Moallem et al., page 5276. Three rumen-fistulated cows in a $3 \times 3$ Latin square design were abomasally infused with $110 \mathrm{~mL} / \mathrm{d}$ of water (control) or 110 or $220 \mathrm{~mL} / \mathrm{d}$ of flaxseed oil (LFO and HFO, respectively). Average dry matter intake and milk yield were not affected by oil infusion. Apparent transfer efficiency of $\alpha$-linolenic acid to milk was 44.8 and $45.7 \%$ with LFO and HFO, resulting in 1.89 and $3.30 \%$-linolenic acid in milk fat, respectively, which was accompanied by elevated C18:2 n-6 and reduced C16:0, suggesting an inverse relationship between these fatty acids.

Effect of treatment with a mixture of bacteria and fibrolytic enzymes on the quality and safety of corn silage infested with different levels of rust. By Queiroz et al., page 5285. This study examined the effect of inoculant treatment on the quality and safety of silage made with corn plants infested with different levels of southern rust. Increasing levels of rust infestation were associated with poorer fermentation, lower nutritive value, and greater aflatoxin contamination. Application of the inoculant decreased most negative effects of rust infestation on the nutritive value, fermentation, and aerobic stability of the silage and prevented accumulation of aflatoxin in the silage.

Adjusting the weaning age of calves fed by automated feeders according to individual intakes of solid feed. By de Passillé and Rushen, page 5292. Adjusting weaning age according to the ability of indi- vidual calves to eat solid feed can help reduce the age at weaning and improve weight gains during weaning. A low target starter intake to begin weaning $(200 \mathrm{~g} / \mathrm{d})$ results in longer weaning duration, earlier weaning, and better growth. A high target to complete weaning (1.6 $\mathrm{kg} / \mathrm{d}$ ) can help prevent weaning from occurring too quickly.

A meta-analysis of variability in continuousculture ruminal fermentation and digestibility data. By Hristov et al., page 5299. Continuous-culture in vitro systems are often used to study ruminal fermentation. The main objective of this meta-analysis was to compare fermentation parameters and data variability between continuous-culture systems and an in vivo dataset from trials with dairy cows. We concluded that continuous-culture systems are characterized by lower fermentation intensity and nutrient digestibilities and greater variability compared with in vivo data.

Mitigation of methane production from cattle by feeding cashew nut shell liquid. By Shinkai et al., page 5308. To mitigate the methane emission from cattle, the effect of cashew nut shell liquid (CNSL) was evaluated in feeding trials. Feeding of CNSL was found to reduce methane production from cattle remarkably without decreasing digestibility of feed. Rumen bacteria populations changed following the administration of CNSL toward species that produce more propionate and less methane. In summary, CNSL can be a useful additive for improving ruminant feed conversion efficiency and for reducing global warming.

Meta-analysis of the effect of pregrazing pasture mass on pasture intake, milk production, and grazing behavior of dairy cows strip-grazing temperate grasslands. By Pérez-Prieto and Delagarde, page 5317. In pasture-based dairy systems, large variation in pasture growth rate, along with different grazing management practices, result in significant variation in pregrazing pasture mass. Under rotationalor strip-grazing management, the effect of pasture mass is generally studied at the same pasture allowances above ground level, at $2,3,4$, or $5 \mathrm{~cm}$, depending on grazing practices. The present meta-analysis allowed for a better understanding of the effect of pasture mass, irrespective of the estimation height, unraveled inconsistent results reported in the literature, and improved the prediction of pasture intake and performance of grazing dairy cows.

Short communication: Addition of sodium bicarbonate to maternal colostrum: Effects on IgG absorption and hematocrit in neonatal calves. By Chapman et al., page 5331. Recent studies have evaluated the effects of adding sodium bicarbonate to colostrum replacer on immunoglobulin absorption in 
newborn calves, which have led to some inconsistent outcomes. In this study, we added $30 \mathrm{~g}$ of sodium bicarbonate to maternal colostrum to observe effects on immunoglobulin uptake in Holstein bull calves over a 48-h period and to determine the effect of adding sodium bicarbonate to colostrum instead of colostrum replacer. Serum immunoglobulin G concentrations were similar in all calves, with or without $30 \mathrm{~g}$ of sodium bicarbonate added to colostrum, indicating no effect of sodium bicarbonate on immunoglobulin $\mathrm{G}$ absorption in calves over the period of study ( $48 \mathrm{~h}$ ). Hematocrit data were also not affected by sodium bicarbonate treatment.

Short communication: Effect of difructose anhydride III on serum immunoglobulin G concentration in newborn calves. By Sato et al., page 5336. Difructose anhydride (DFA) III is an indigestible disaccharide that promotes paracellular absorption of minerals. We showed that, in newborn calves, DFA III supplementation affects serum immunoglobulin $\mathrm{G}(\mathrm{IgG})$ levels, increasing apparent efficiency of IgG absorption as well as the height of the regression line of serum IgG against colostral IgG. We conclude that DFA III alleviates failure of transfer of passive immunity and has some advantages in health and viability of newborn calves.

Short communication: Characterization of Shiga toxin-producing Escherichia coli isolated from newborn, milk-fed and growing calves in Argentina. By Fernández et al., page 5340. Shiga toxinproducing Escherichia coli (STEC) are causative agents of hemolytic-uremic syndrome (HUS), which is endemic in Argentina. Human transmission is mediated through feces of cattle or consumption of undercooked meat, nonpasteurized dairy products and vegetables, or contaminated water. In this study, rectal swabs from dairy calves were analyzed by PCR to detect Shiga toxins 1 and 2 (Stx1 and Stx2), the main virulence factors of STEC. In newborn, milk-fed, and growing calves, we found different STEC serotypes previously associated with severe disease in humans. The STEC strains could be acquired early in life, enabling the infection of other animal categories and confirming the risk to public health.

Comparative evaluation of a new lactation curve model for pasture-based Holstein-Friesian dairy cows. By Adediran et al., page 5344. Fourteen lactation models were compared with 2 forms of a new log-quadratic model using test-day milk yield data from pasture-based Holstein-Friesian cows. The goodness of fit of all but two of the models was similar for average lactation, but differed in predicting initial, peak, and total milk yields. The new model was more parsimonious and performed better than some of the existing models, and we propose its use for modeling lactation in pasture-based dairy cows.

Genome-wide association mapping of milk production traits in Braunvieh cattle. By Maxa et al., page 535\%. The main aim of this study was to set up a whole genome association scan of the main milk production traits in Braunvieh cattle, considering family relationships within a structured population. The Braunvieh population is spread mainly across the Alpine regions of several European countries. Because of the admixed status of this breed and the family relationships, we applied correction for population stratification in this study. The results contribute to the mapping of corresponding quantitative trait loci.

Estimation of genetic parameters for test-day records of dairy traits in a seasonal calving system. By McCarthy and Veerkamp, page 5365. Genetic parameters for milk yield are usually estimated in cow populations involved in year-round production. The Irish production system is seasonal, with cows beginning lactation coinciding with grass availability. To investigate this effect of seasonality, genetic parameters were estimated by including stage of year and stage of lactation in the analysis. Although negative genetic correlations were found between different stages of the year, seasonality explained little extra genetic variation. This suggests no additional benefit in accounting for the effect of seasonality on the genetic parameters with the current analysis.

Multibreed genomic evaluations using purebred Holsteins, Jerseys, and Brown Swiss. By Olson et al., page 5378. Genotypes of purebred Holstein, Jersey, and Brown Swiss were used to predict genomic merit across all breeds. Three different evaluation methods were investigated. A method that predicted merit in one breed using training data from another breed worked poorly. A method that combined all breeds into one population had higher accuracies than parent average but was not as accurate as predictions within breed. A correlated trait model in which traits were the marker effects in each breed increased the accuracy of genomic predictions above the within-breed estimates.

Costs for health care of Holstein cows selected for large versus small body size. By Becker et al., page 5384. In a long-term selection project, Holstein cows selected for large body size had significantly higher total health costs in first lactation (\$62.41 vs. \$41.41) and tended to have higher total health costs averaged across the first 3 lactations (\$54.15 vs. $\$ 38.09$ ) compared with Holstein cows selected for small body size. Among 11 categories of health care, large-line cows had higher cost for displaced abomasum and pneumonia 
than did small-line cows during first lactation. Across the first 3 lactations, large-line cows had significantly higher health care costs for locomotion and displaced abomasum than did small-line cows. Continued selection for large body size in Holsteins may not be economically justifiable.

Genetic parameters for energy balance, feed efficiency, and related traits in Holstein cattle. By Spurlock et al., page 5393. Individual feed intake and production data were recorded for 402 Holstein cows from 2 through $150 \mathrm{~d}$ in milk. A significant genetic component in the regulation of feed intake, energy balance, and gross feed efficiency was observed. Additionally, the genetic regulation of energy balance differed with stage of lactation. An unfavorable genetic correlation was found between overall efficiency and energy balance in the first month of lactation. However, this genetic correlation was reduced when gross feed efficiency was calculated between 75 and $150 \mathrm{~d}$ in milk. Therefore, it may be feasible to improve efficiency without detrimental changes to energy balance during early lactation.

Reliability of genomic prediction for German Holsteins using imputed genotypes from lowdensity chips. By Segelke et al., page 5403. With low-density chips, breeders can genomically evaluate their herds at lower cost. To assess the accuracy of genomic prediction with low-density chips in relation to the BovineSNP50 chip (Illumina Inc., San Diego, CA), missing genotypes of low-density chips Bovine $3 \mathrm{~K}(3,000$ single nucleotide polymorphisms, SNP) and BovineLD (6,000 SNP) were imputed by applying programs Beagle and Findhap. The allele error rate was highest for Findhap 3K, and lowest for Beagle 6K. Compared with using original genotypes, loss in reliability of genomic prediction with the imputed genotypes was largest for Findhap 3K and smallest for Beagle $6 \mathrm{~K}$.

The impact of genotyping different groups of animals on accuracy when moving from traditional to genomic selection. By Pszczola et al., page 5412. Compared with traditional selection, genomic selection increases the accuracy of estimated breeding values. The aim of this study was to investigate whether this increase is mainly due to genotyping reference or evaluated animals. Having genomic relationships is less important for reference animals than for evaluated animals without phenotypic observations. Nevertheless, genotyping only one group always yields substantially less accurate estimates than when both reference and evaluated animals are genotyped. Knowing genomic relationships also improves connectedness between reference and evaluated animals, and thereby reduces evaluation bias.

Incidence validation and relationship analysis of producer-recorded health event data from onfarm computer systems in the United States. By Parker Gaddis et al., page 5422. Substantial progress has been made in the genetic improvement of production traits while health and fitness traits of dairy cattle have declined. Data collected from on-farm computer management systems may provide an effective and lowcost source of health information. The current study sought to examine the plausibility of producer-recorded health data throughout the United States on a large scale. Relationships were examined between diseases to add to the credibility of the data. The results provide evidence that producer-recorded data sufficiently represent the true incidence of health events.

Short communication: Evaluation of bovine milk residues from routine milk testing programs as DNA source for genotyping. By Krappmann et al., page 5436. Collection of the large number of samples required for genomic evaluation and genome-wide association studies contributes substantially to the costs of the method. In dairy cattle research, a cost-saving alternative would be the use of sample residues from routine milk recording. To evaluate this low-cost alternative, we genotyped milk residues and corresponding blood samples from 115 cows in parallel. Milk residues are not suitable for genomic evaluation and genomewide association studies because at least $27 \%$ of the samples were contaminated by foreign DNA and, in at least $4 \%$ of the samples, an incorrect identity had to be assumed.

A daily herd Markov-chain model to study the reproductive and economic impact of reproductive programs combining timed artificial insemination and estrus detection. By Giordano et al., page 5442. Dairy herd profitability is closely associated with reproductive performance. However, predicting the effect of reproductive management programs on the dynamics and economics of dairy herds is complex. Thus, we created a comprehensive simulation model to replicate herd dynamics using programs combining estrus detection and timed artificial insemination of cows. Value of the reproductive program depended on the proportion of cows inseminated after estrus detection and the resulting conception rate. 